\title{
Influence of temperature on germination of uredniospores of Puccinia recondita f. sp. tritici
}

\author{
Wpływ temperatury na kiełkowanie urediniospor \\ Puccinia recondita f. sp. tritici
}

\author{
Andrzej Wójtowicz, Romuald Gwiazdowski, Krzysztof Kubiak, Maria Pasternak
}

\section{Summary}

The aim of the study was to estimate the influence of temperature on germination of Puccinia recondita f. sp. tritici urediniospores and to determine the relations between spore germination and infection of wheat caused by wheat leaf rust. The following temperatures were examined in the experiments: $5,10,20$, and $30^{\circ} \mathrm{C}$. The most urediniospores germinated at the temperature set up at $15^{\circ} \mathrm{C}$. Results of the study allowed to state the relations between analysed parameters by using mathematical equations. Moreover, the influence of temperature on infection was defined based on experiments and data presented in literature. The Pearson Correlation Coefficient was used to show the relation between spore germination and infection. The study confirmed close relations between analysed variables.

Key words: Puccinia recondita f. sp. tritici, wheat, spore germination, model

\section{Streszczenie}

Celem pracy było oszacowanie wpływu temperatury na kiełkowanie urediniospor Puccinia recondita f. sp. tritici oraz określenie związku tego procesu z infekcją pszenicy przez sprawcę rdzy brunatnej pszenicy. W badaniach zastosowano następujące wartości temperatury: $5,10,20, \mathrm{i} 30^{\circ} \mathrm{C}$. Najwięcej kiełkujących zarodników stwierdzono w temperaturze $15^{\circ} \mathrm{C}$. Uzyskane wyniki pozwoliły na wyrażenie zależności pomiędzy badanymi cechami za pomocą równań matematycznych. Przeprowadzone obliczenia umożliwiły ponadto określenie wpływu temperatury na infekcję pszenicy przez $P$. recondita f. sp. tritici. Do oceny relacji występujących pomiędzy kiełkowaniem urediniospor i infekcją wykorzystano analizę korelacji. Na podstawie współczynnika korelacji Pearsona wykazano ścisły związek pomiędzy kiełkowaniem urediniospor i efektywnością infekcji.

Słowa kluczowe: Puccinia recondita f. sp. tritici, pszenica, kiełkowanie zarodników, model

Instytut Ochrony Roślin - Państwowy Instytut Badawczy

Władysława Węgorka 20, 60-318 Poznań

A.Wojtowicz@iorpib.poznan.pl; R.Gwiazdowski@iorpib.poznan.pl;

K.Kubiak@iorpib.poznan.pl; M.Pasternak@iorpib.poznan.pl 


\section{Wstęp / Introduction}

Infekcja roślin przez patogeny jest złożonym procesem składającym się z kilku następujących po sobie etapów, których przebieg jest regulowany przez szereg czynników. Pierwszym etapem tego procesu jest kiełkowanie zarodników. Puccinia recondita f. sp. tritici sprawca rdzy brunatnej pszenicy należy do gatunków pełnocyklowych, charakteryzujących się wytwarzaniem pięciu rodzajów zarodników: bazydiospor, spermacji, ecjospor, urediniospor i teliospor. Największą rolę w rozwoju epidemii wywoływanej na pszenicy przez $P$. recondita f. sp. tritici odgrywają urediniospory, które są typowymi zarodnikami propagacyjnymi służącymi do rozprzestrzeniania grzyba na plantacjach pszenicy. Kiełkowanie urediniospor $P$. recondita f. sp. tritici zachodzi w szerokim zakresie temperatury wynoszącym $1-30^{\circ} \mathrm{C}$. Wiadomo jednak, że intensywność procesów biologicznych podlega zmianom, w zależności od wartości parametrów stymulujących ich przebieg. Istnieje zatem potrzeba prowadzenia badań zmierzających do opracowania wpływu warunków środowiskowych na rozwój patogena. Takie podejście jest między innymi prezentowane $\mathrm{w}$ badaniach nad rolą temperatury i światła w procesie kiełkowania zarodników grzybów rodzaju Puccinia (Waggoner i Parlange 1975; Tapsoba i Wilson 1997; Dooley 1984; Elahinia 2000; Buck i wsp. 2010).

Celem pracy było oszacowanie wpływu temperatury otoczenia na kiełkowanie urediniospor oraz określenie związku tego procesu $\mathrm{z}$ infekcją pszenicy przez sprawcę rdzy brunatnej pszenicy.

\section{Materiały i metody / Materials and methods}

Doświadczenie przeprowadzono w warunkach laboratoryjnych i szklarniowych w maju 2012 r. Urediniospory pozyskiwano $\mathrm{z}$ pszenicy ozimej odmiany Turnia, po 12-14 dniach od inokulacji grzybem $P$. recondita $f$. sp. tritici. Z porażonych liści za pomocą skalpela pozyskiwano uredinia, które przenoszono do fiolki ze sterylną wodą dejonizowaną, a następnie całość umieszczano w wytrząsarce. Koncentracja zarodników wynosiła $2,7 \times 10^{6} / \mathrm{ml}$. Tak przygotowaną zawiesinę zarodników nanoszono w równej objętości na szkiełka podstawowe pokryte cienką warstwą pożywki PDA (Potato Dextrose Agar) lub pożywki PDA z dodatkiem soku z roztartych liści pszenicy. Na szkiełka podstawowe nakładano szkiełka nakrywkowe i tak przygotowane preparaty umieszczano na płytkach Petriego o średnicy $200 \mathrm{~mm}$, których dno wyłożono warstwą wilgotnej bibuły filtracyjnej. Dodatkowo płytki umieszczono w szczelnych workach foliowych, a następnie inkubowano je w temperaturach: $5,10,15,20$ i $30^{\circ} \mathrm{C}$. Na każdy wariant temperatury przypadały 4 powtórzenia (szkiełka podstawowe). Po 24 godzinach inkubacji przeprowadzono obserwację mikroskopową przy 200-krotnym powiększeniu. Z każdego szkiełka podstawowego wybierano 3 pola widzenia, a następnie w każdym z pól na podstawie 10 zarodników określano odsetek zarodników kiełkujących. Doświadczenie przeprowadzono dwukrotnie. Za pomocą równania matematycznego określono wpływ temperatury na kiełkowanie zarodników.
Zarodniki propagacyjne $P$. recondita f. sp. tritici wykorzystano także do zakażania zdrowych siewek pszenicy. Do tego celu używano wodnej zawiesiny urediniospor (koncentracja zarodników wynosiła 3,1 × $10^{6} / \mathrm{ml}$ ), którą opryskiwano rośliny za pomocą atomizera. Inokulowane rośliny wkładano do szczelnych pojemników gwarantujących utrzymanie zwilżenia liści i przez 24 godziny poddawano temperaturze $5,10,20$ i $25^{\circ} \mathrm{C}$. Następnie rośliny wyjmowano $\mathrm{z}$ pojemników i umieszczano w temperaturze $20^{\circ} \mathrm{C}$. Liczenie urediniów odbywało się 12 dni po inokulacji. Doświadczenie przeprowadzono dwukrotnie. Uzyskane wyniki wykorzystano do wyrażenia w formie funkcji beta wpływu temperatury na intenywność infekcji. Oprócz tego do symulacji wpływu temperatury w procesie infekcji pszenicy przez $P$. recondita wykorzystano model opracowany na podstawie wyników badań Vallavielle-Pope i wsp. (1995). W celu oszacowania związku procesu kiełkowania zarodników z infekcją oceniono za pomocą współczynnika korelacji Pearsona zbieżność rezultatów badań nad kiełkowaniem zarodników z wynikami prezentującymi rolę temperatury $\mathrm{w}$ procesie infekcji.

\section{Wyniki i dyskusja / Results and discussion}

W eksperymentach przeprowadzonych $\mathrm{z}$ zastosowaniem pożywki PDA największy odsetek kiełkujących zarodników wynoszący $60 \% \mathrm{w}$ doświadczeniu pierwszym i $70 \% \mathrm{w}$ doświadczeniu drugim stwierdzono w rezultacie prowadzenia analizowanego procesu w temperaturze $15^{\circ} \mathrm{C}$ (tab. 1). Zmniejszenie liczby kiełkujących uredioniospor do $43 \%$ w doświadczeniu pierwszym i 34\% w doświadczeniu drugim odnotowano w następstwie obniżenia temperatury do $10^{\circ} \mathrm{C}$. $35 \%$ oraz $55 \%$ kiełkujących zarodników w doświadczeniach: pierwszym i drugim było efektem zastosowania temperatury $20^{\circ} \mathrm{C}$. Obniżenie temperatury eksperymentu do $5^{\circ} \mathrm{C}$ ograniczyło liczbę kiełkujących zarodników do $31 \% \mathrm{w}$ doświadczeniu pierwszym i $20 \%$ w doświadczeniu drugim. Najmniej kiełkujących urediniospor stwierdzono $\mathrm{w}$ wyniku zastosowania temperatury $30^{\circ} \mathrm{C}$. W tych warunkach $\mathrm{w}$ doświadczeniu pierwszym odnotowano $11 \%$ kiełkujących zarodników, a w doświadczeniu drugim $8 \%$.

W eksperymentach przeprowadzonych na pożywce PDA z dodatkiem soku największą liczbę kiełkujących zarodników $P$. recondita f. $\mathrm{sp}$. tritici wynoszącą w pierwszym doświadczeniu $38 \%$ oraz $47 \%$ w drugim doświadczeniu odnotowano w efekcie zastosowania temperatury $15^{\circ} \mathrm{C}$. Obniżenie temperatury do $10^{\circ} \mathrm{C}$ spowodowało zmniejszeniem liczby kiełkujących urediniospor do $28 \% \mathrm{w}$ doświadczeniu pierwszym i $22 \% \mathrm{w}$ doświadczeniu drugim. Liczba kiełkujących zarodników w doświadczeniach pierwszym i drugim odnotowana w rezultacie zastosowania temperatury $20^{\circ} \mathrm{C}$ wynosiła odpowiednio 18 i 28\%. Natomiast 12\% kiełkujących zarodników w doświadczeniu pierwszym i $15 \%$ w doświadczeniu drugim wykazały eksperymenty przeprowadzone w temperaturze $5^{\circ} \mathrm{C}$. Najmniejszą liczbę kiełkujących uredinio spor wynoszącą $\mathrm{w}$ doświadczeniu pierwszym $6 \%$ oraz $2 \%$ $\mathrm{w}$ doświadczeniu drugim odnotowano $\mathrm{w}$ rezultacie przeprowadzenia badań $\mathrm{w}$ temperaturze $30^{\circ} \mathrm{C}$. Wyniki 


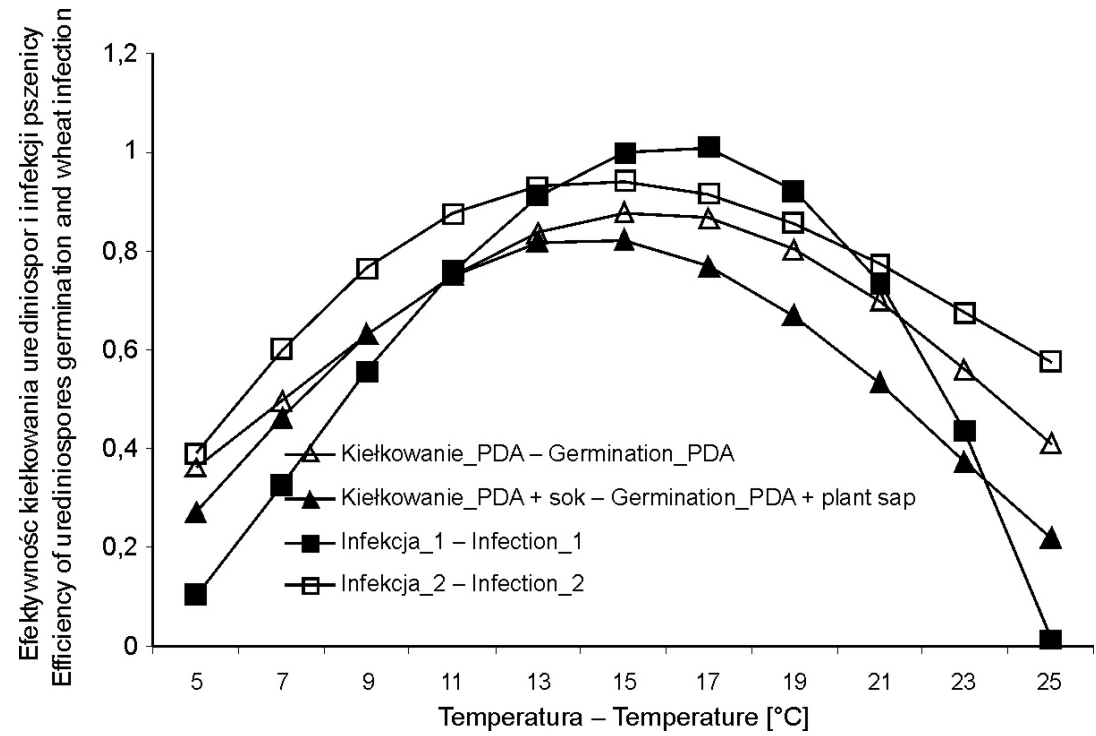

Rys. 1. Graficzne przedstawienie wpływu temperatury na kiełkowania urediniospor P. recondita f. sp. tritici oraz wystapienia infekcji pszenicy

Fig. 1. Graphical presentation of temperature influence on $P$. recondita f. sp. tritici urediniospores germination and wheat infection

Tabela 1. Wpływ temperatury na kiełkowanie urediniospor $P$. recondita f. sp. tritici

Table 1. Influence of temperature on urediniospores germination of $P$. recondita $\mathrm{f}$. sp. tritici

\begin{tabular}{c|c|c|c|c}
\hline \multirow{2}{*}{$\begin{array}{c}\text { Temperatura } \\
\text { Temperature } \\
{\left[{ }^{\circ} \mathrm{C}\right]}\end{array}$} & \multicolumn{3}{|c}{ Procent kiełkujących urediniospor - Percentage of germianting urediniospores } \\
\cline { 2 - 5 } & PDÁwiadczenie 1 - experiment 1 & \multicolumn{2}{c}{ doświadczenie $2-$ experiment 2} \\
\cline { 2 - 5 } & $31 \mathrm{bc}$ & $\begin{array}{c}\text { PDA + sok } \\
\text { PDA + plant sap }\end{array}$ & PDA & $\begin{array}{c}\text { PDA sok } \\
\text { PDA + plant sap }\end{array}$ \\
\hline 5 & $43 \mathrm{~b}$ & $12 \mathrm{cb}$ & $20 \mathrm{bc}$ & $15 \mathrm{bc}$ \\
\hline 10 & $60 \mathrm{a}$ & $28 \mathrm{~b}$ & $34 \mathrm{~cd}$ & $47 \mathrm{a}$ \\
\hline 15 & $35 \mathrm{~b}$ & $38 \mathrm{ab}$ & $70 \mathrm{a}$ & $28 \mathrm{~b}$ \\
\hline 20 & $11 \mathrm{c}$ & $18 \mathrm{bc}$ & $55 \mathrm{a}$ & $2 \mathrm{c}$ \\
\hline 30 & $6 \mathrm{c}$ & $8 \mathrm{~d}$ & \\
\hline
\end{tabular}

W kolumnach różnymi literami oznaczono wartości różniące się istotnie przy poziomie $\alpha=0,05$

The columns with different letters denote values that differ significantly at the level of $\alpha=0.05$

Tabela 2. Wpływ temperatury na liczbę urediniów $P$. recondita f. sp. tritici na siewkach pszenicy

Table 2. Influence of temperature on number of $P$. recondita $\mathrm{f}$. sp. tritici uredinia on wheat seedlings

\begin{tabular}{c|c|c}
\hline $\begin{array}{c}\text { Temperatura - Temperature } \\
{\left[{ }^{\circ} \mathrm{C}\right]}\end{array}$ & Doświadczenie 1 - Experiment 1 & Doświadczenie 2 - Experiment 2 \\
\hline 5 & $7 \mathrm{c}$ & $8 \mathrm{c}$ \\
\hline 10 & $45 \mathrm{~b}$ & $49 \mathrm{~b}$ \\
\hline 15 & $66 \mathrm{a}$ & $76 \mathrm{a}$ \\
\hline 20 & $55 \mathrm{ab}$ & $65 \mathrm{a}$ \\
\hline 25 & $1 \mathrm{c}$ & $1 \mathrm{c}$ \\
\hline
\end{tabular}

W kolumnach różnymi literami oznaczono wartości różniące się istotnie przy poziomie $\alpha=0,05$

The columns with different letters denote values that differ significantly at the level of $\alpha=0.05$

Tabela 3. Współczynnik korelacji infekcji z kiełkowaniem urediniospor $P$. recondita f. sp. recondita

Table 3. Correlation coefficient between infection and uredniospore germination of $P$. recondita $\mathrm{f}$. sp. recondita

\begin{tabular}{l|c|c}
\hline \multicolumn{1}{c|}{$\begin{array}{c}\text { Infekcja } \\
\text { Infection }\end{array}$} & Kiełkowanie urediniospor na - Germination of urediniospores on \\
\cline { 2 - 3 } & 0,98919 & PDA + sok - PDA + plant sap \\
\hline Infekcja_1 - Infection_1 & 0,97496 & 0,903545 \\
\hline Infekcja_2-Infection_2 & 0,931891 \\
\hline
\end{tabular}


analizy wariancji przeprowadzonej $\mathrm{z}$ zastosowaniem danych uzyskanych w przeprowadzonych badaniach nad wpływem temperatury na kiełkowanie urediniospor $P$. recondita $\mathrm{f}$. sp. tritici przedstawiono w tabeli 1.

Uzyskane wyniki są zgodne z rezultatami eksperymentów Vallavielle-Pope i wsp. (1995) nad wpływem temperatury $\mathrm{w}$ zakresie $5-35^{\circ} \mathrm{C}$ na kiełkowanie urediniospor $P$. recondita f. sp. tritici. Największą liczbę kiełkujących zarodników w tych doświadczeniach stwierdzono w temperaturze $15^{\circ} \mathrm{C}$, a najmniejszą w następstwie zastosowania temperatury $35^{\circ} \mathrm{C}$. W temperaturze $30^{\circ} \mathrm{C}$ kiełkowało mniej urediniospor niż $\mathrm{W}$ temperaturach niższych, a w temperaturach 10 i $20^{\circ} \mathrm{C}$ proces kiełkowania przebiegał intensywniej niż $\mathrm{w}$ temperaturze $5^{\circ} \mathrm{C}$. Zbieżne z wynikami badań własnych są również rezultaty doświadczeń Eversmeyera i wsp. (1988), którzy w doświadczeniach ukierunkowanych na poznanie procesu kiełkowania urediniospor $P$. recondita f. sp. tritici zastosowali temperaturę $\mathrm{w}$ zakresie $12-20^{\circ} \mathrm{C}$ i wykazali największą liczbę kiełkujących zarodników w temperaturze $16^{\circ} \mathrm{C}$. Termiczną stymulację procesu kiełkowania urediniospor P. recondita f. sp. tritici potwierdzają również wyniki eksperymentów Tollenaara (1985), który w badaniach nad kiełkowaniem urediniospor $P$. recondita f. $\mathrm{sp}$. tritici zastosował następujące temperatury: 0, 4, 8, 24, 28, 30, 32, $34,36^{\circ} \mathrm{C}$. W tych warunkach największą liczbę kiełkujących zarodników stwierdzono w temperaturze $20^{\circ} \mathrm{C}$. Podwyższanie i obniżanie temperatury prowadzenia eksperymentu skutkowało zmniejszeniem liczby kiełkujących zarodników.

Wyniki badań własnych nad wpływem temperatury na proces kiełkowania zarodników wyrażono w formie następujących równań:

$$
\begin{aligned}
& \text { KIEŁK }^{\mathrm{PDA}+\text { sok }}=0,000039 \times\left((\mathrm{T}-1,074)^{1,689}\right. \\
&\left.\times(30,0001-\mathrm{T})^{2,036}\right) \\
& \mathrm{KIEL}^{\mathrm{PDA}}= 2,82 \mathrm{E}-15 \times\left((\mathrm{T}-(-12,7887))^{5,596427}\right. \\
&\left.\times(39,13517-\mathrm{T})^{4,638157}\right)
\end{aligned}
$$

$\mathrm{KIEKK}^{\mathrm{PDA}+\text { sok }}$ - intensywność kiełkowania na pożywce PDA z sokiem z roślin pszenicy,

$\mathrm{KIEŁK}^{\mathrm{PDA}}$ - intensywność kiełkowania na pożywce PDA, $\mathrm{T}$ - temperatura $\left[{ }^{\circ} \mathrm{C}\right]$.
W doświadczeniach ukierunkowanych na ocenę wpływu temperatury na nasilenie objawów chorobowych najwięcej urediniów stwierdzono w efekcie zastosowania temperatury $15^{\circ} \mathrm{C}$ (tab. 2). Obniżanie i podwyższanie temperatury prowadzenia eksperymentu skutkowało istotnym zmniejszeniem liczby urediniów.

Wyniki doświadczeń nad rolą temperatury w procesie infekcji wyrażono w formie następującej funkcji:

$$
\begin{aligned}
\text { Infekcja_1 } & =0,003332 \times\left((\mathrm{T}-3,579)^{1,405}\right. \\
& \left.\times(25,055-\mathrm{T})^{0,988}\right)
\end{aligned}
$$

Na podstawie danych literaturowych zaprezentowanych w badaniach Vallavielle-Pope i wsp. (1995) opracowano następujące równanie:

$$
\begin{aligned}
\text { Infekcja_2 }^{2} & =0,00000014 \times\left((\mathrm{T}-1,095)^{1,447}\right. \\
& \left.\times(51,2008-\mathrm{T})^{3,9584}\right)
\end{aligned}
$$

Przebieg analizowanych funkcji przedstawiono na rysunku 1. Przeprowadzona analiza korelacji wykazała ścisły związek pomiędzy kiełkowaniem urediniospor i efektywnością infekcji (tab. 3). Współczynnik korelacji Pearsona uzyskany jako rezultat porównania wpływu temperatury na kiełkowanie urediniospor na pożywce PDA z efektywnością infekcji oszacowanej na podstawie badań własnych i modelu opracowanego z wykorzystaniem danych literaturowych wynosił odpowiednio 0,99 i 0,97. Nieznacznie mniejsze wartości współczynnika korelacji wynoszące 0,90 i 0,93 odnotowano, kiedy w obliczeniach uwzględniono wyniki doświadczeń, w których kiełkowanie zarodników odbywało się na pożywce PDA z dodatkiem soku $\mathrm{z}$ roślin pszenicy.

\section{Wnioski / Conclusions}

1. Uzyskane wyniki potwierdzają wpływ temperatury na kiełkowanie urediniospor $P$. recondita f. sp. tritici oraz znaczenie tego czynnika $w$ procesie infekcji pszenicy przez $P$. recondita $\mathrm{f}$. sp. tritici.

2. Rezultaty przeprowadzonych badań wskazują na ścisły związek efektywności procesu infekcji z kiełkowaniem zarodników.

\section{Literatura / References}

Buck J.W., Dong W., Mueller D.S. 2010. Effect of light exposure on in vitro germination and germ tube growth of eight species of rust fungi. Mycologia 102 (5): 1134-1140.

Dooley H.L. 1984. Temperature effect on germination of uredospores of Melampsoridium betulinum and on rust development. Plant Dis. 68: 686-688.

Elahinia S. 2000. Assessment of urediniospore germination of Puccinia striiformis at various temperatures on agar and detached leaves of wheat. J. Agr. Sci. Tech. 2: 41-47.

Eversmeyer M.G., Kramer C.L., Hassan Z.M. 1988. Environmental influences on the establishment of Puccinia recondita infection structures. Plant Dis. 72 (5): 409-412.

Tapsoba H., Wilson J.P. 1997. Effects of temperature and light on germination of urediniospores of the pearl millet rust pathogen, Puccinia substriata var. indica. Plant Dis. 81: 1049-1052.

Tollenaar H. 1985. Uredospore germination and development of some cereal rusts from south-central chile at constant temperatures. Phytopathol. Z. 114: 118-125.

Vallavielle-Pope C., Huber L., Leconte M., Goyeau H. 1995. Comparative effects of temperature and interrupted wet periods on germination, penetration, and infection of Puccinia recondita f. sp. tritici and P. striiformis on wheat seedlings. Phytopathology 85: 409-415.

Waggoner P.E., Parlange J. 1975. Slowing spore germination with changes between moderately warm and cool temperatures. Phytopathology 65: 551-553. 